\title{
Embedding Covid-safe behaviours into everyday life through an enhanced risk management approach
}

\author{
Susan Michie ${ }^{1}$, Robert West ${ }^{1}$ \\ 1 University College London, University of London \\ Funding: The author(s) received no specific funding for this work. \\ Potential competing interests: The author(s) declared that no potential competing interests exist.
}

\begin{abstract}
Covid-19 is likely to be with us for many years, and the threat of future pandemics is high. Societies worldwide need to develop policies to minimise the impact of Covid-19 and the risk of future pandemics, and mitigate the harm caused by those pandemics when they occur. These policies need to work alongside strategies for tackling climate change and other threats to the lives and wellbeing of the global population. They also need to facilitate rather than restrict progress in combating poverty and inequality.
\end{abstract}

\section{Definitions}

\section{Behaviour}

Defined by Susan Michie

Policies to combat pandemics require large-scale changes in behaviours, social and material environments, societal and public health systems and health services. ${ }^{[1]}$ These have been variously termed, with the vague medical term 'NPIs' (nonpharmaceutical interventions) being replaced by BESSIs (Behavioural, Environmental, Social and Systems Interventions. ${ }^{[2]}$ No single type of intervention will be sufficient but multiple layers can provide effective reduction, as illustrated by the 'Swiss cheese' model of risk management, ${ }^{\left[{ }^{[3]}\right.}$ with holes in different places in different layers providing a greater chance of blocking the infection pathway (Figure 1). 


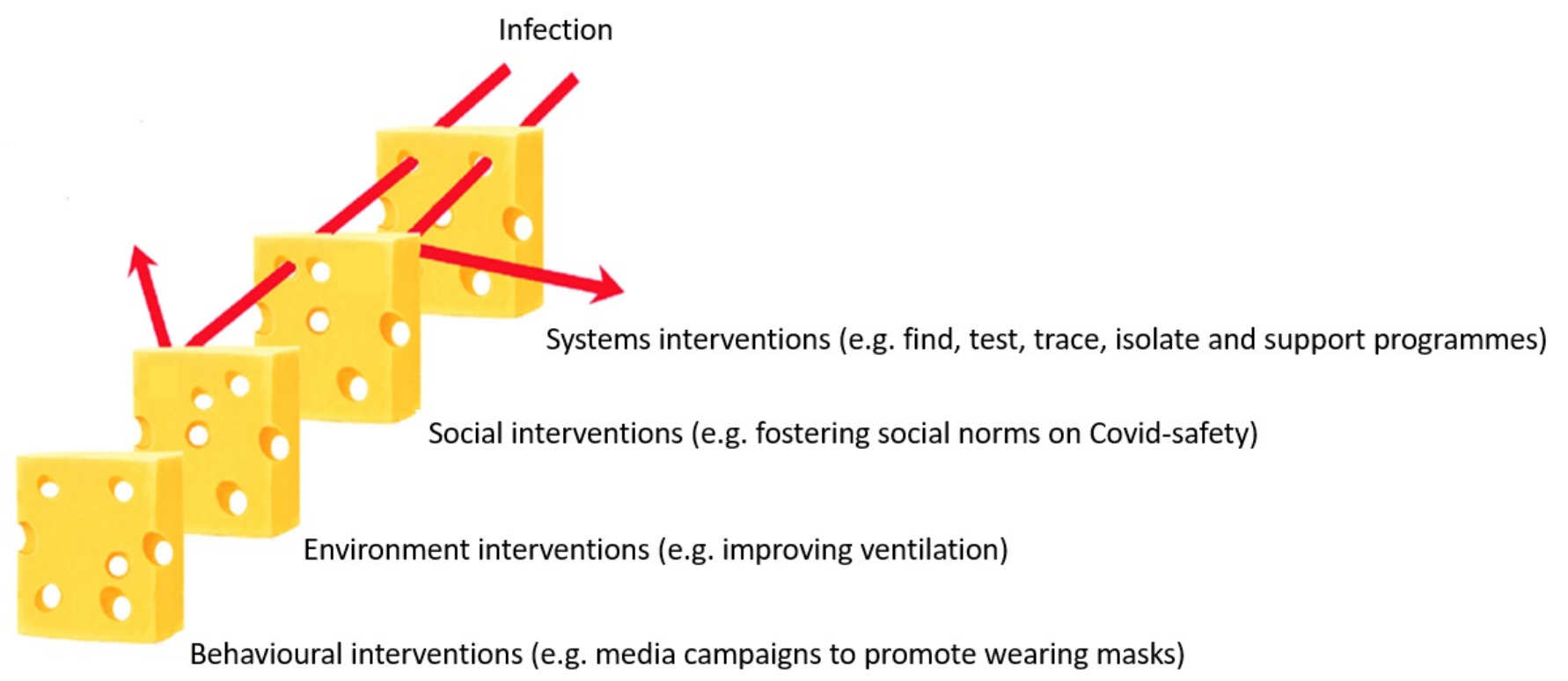

Figure 1. "Swiss" cheese model applied to behavioural, environmental, social and systems interventions to combat Covid-19

Embedding new patterns of human behaviour is a crucial target for policies to address the threat from pandemics. Behaviour change will be needed in all sectors of society: the general public, businesses, non-governmental organisations, civil servants and politicians.

Large scale behaviour change to tackle global issues is possible. It has occurred throughout history and continues to occur. Improved hygiene behaviour to reduce infection from enteric and respiratory pathogens has been a significant factor in the considerable improvement in human life expectancy seen in the past 200 years ${ }^{[4]}$ In many parts of the world, we are currently witnessing significant reductions in tobacco use that are further adding to longevity. ${ }^{[5]}$ And the risk of death and injury has been slashed through improved risk-management behaviours in transport and workplaces. ${ }^{[6]}$

We have already seen unprecedented behaviour change in response to Covid-19, which remains the single most crucial factor in limiting its transmission and harm. ${ }^{[2]}$ In order to suppress transmission and protect communities and services, people have been willing to accept extremely demanding and punishing restrictions, repeatedly and for extended periods. ${ }^{[7]}$

The damage that many of these restrictions have caused to people's lives and wellbeing means that they are not sustainable long term. Countries need to move to a new pandemic control and mitigation phase involving 'enhanced risk mitigation' strategies. These must combine vaccination programmes with structural and behavioural programmes that can be maintained and are compatible with human development goals. ${ }^{[2]}$

Key individual behaviours that reduce Covid-19 transmission have been clearly identified ${ }^{[8]}$ Table 1 lists these behaviours. No single behaviour would be sufficient, but together they can form a highly effective barrier to transmission. In an enhanced risk-management approach, the level of risk prevailing at the time and in the locality will determine how 
rigorously people need to enact them. ${ }^{[9]}$ They will need to be supported by actively monitoring risk levels and providing social and material support to others to help build a Covid-safe culture.

Table 1. Citizens' behaviours that reduce spread of Covid-19

\begin{tabular}{|c|c|}
\hline Behaviours & Details \\
\hline Getting vaccinated & Vaccination greatly reduces the risk of becoming infected, transmitting the virus, and being seriously ill or dying if infected. \\
\hline Getting tested regularly & $\begin{array}{l}\text { Getting tested regularly, particularly before engaging in high contact events, is crucial to establishing infectiousness but must be } \\
\text { accompanied by isolation when required. }\end{array}$ \\
\hline $\begin{array}{l}\text { Isolating when potentially } \\
\text { infectious }\end{array}$ & $\begin{array}{l}\text { Isolating when potentially infectious (because of symptoms, or after a positive test result, exposure to infection, or travelling from } \\
\text { a high-risk setting) is a cornerstone of infection control. }\end{array}$ \\
\hline $\begin{array}{l}\text { Maximising ventilation when } \\
\text { indoors }\end{array}$ & Ensuring high turnover of fresh air in indoor spaces is highly effective in reducing infection rates. \\
\hline $\begin{array}{l}\text { Limiting the use of public } \\
\text { indoor areas }\end{array}$ & Indoor areas pose a much greater risk than outdoor areas, particularly when crowded. \\
\hline Social distancing & $\begin{array}{l}\text { Maintaining a distance of } 2 \mathrm{~m} \text { or more from others reduces the risk of infection. It is achievable in many settings without being } \\
\text { disruptive. }\end{array}$ \\
\hline Wearing a protective mask & $\begin{array}{l}\text { Evidence now strongly indicates that wearing a well-fitting N95 or FFP2 mask or similar over the mouth and nose reduces the risk } \\
\text { of being infected and infecting others. }\end{array}$ \\
\hline Hand and surface hygiene & $\begin{array}{l}\text { Regularly disinfecting hands through washing with soap or using hand sanitiser, and ensuring surfaces are regularly disinfected, } \\
\text { reduces the risk of exposure through contact. }\end{array}$ \\
\hline $\begin{array}{l}\text { Hygienically trapping coughs } \\
\text { and sneezes }\end{array}$ & $\begin{array}{l}\text { Catching large droplets produced by coughing and sneezing in a suitable material and safely disposing of this reduces } \\
\text { transmission of the virus. }\end{array}$ \\
\hline Restricting travel & Restricting travel reduces the risk of seeding infections in communities that currently have no infections. \\
\hline
\end{tabular}

Societies will need to put in place physical and social changes to their infrastructure to maximise the capability, opportunity and motivation to engage in these behaviours as required and to minimise their adverse impact, as outlined in the COM-B model of behaviour. ${ }^{[10]}$ The 'NEAR' principle can help guide these changes: focusing on making behaviours Normal, Easy, Attractive, and Routine. ${ }^{[10]}$ There is extensive evidence to shape policies to achieve this. It requires action by all sectors of society, including central and local government, the commercial and voluntary sectors, and the public.

Individual behaviour change is only one layer in the 'Swiss cheese' approach ${ }^{[2]}$ Governments, business and all parts of civil society have a role to play in the enhanced risk management strategy which ensure that everyone has the capability, opportunity and motivation to behave in ways that reduce infection risk. Table 2 summarises policies that have been identified as important.

Table 2. Policies to maximise the capability, opportunity and motivation to engage in Covid-safe behaviours. 


\begin{abstract}
Policy
target

Details

Capability

All sectors of society in all localities and settings need to understand the level of risk they currently face. They need to know where that risk comes from, and the benefits and costs of potential mitigation measures. Social marketing campaigns, easy access to information resources, and education programmes are required to maximise understanding of risk and effective risk mitigation in all communities.

Individuals and organisations require easy access to material, social and financial resources. These resources must be commensurate with the

Opportunity need: for example, ensuring sufficient financial support for self-isolation, provision for people to work from home, easy access to vaccination, easy access to testing, easy access to suitable face masks, availability of hygiene facilities, spatial layouts that facilitate social distancing, access to outdoor leisure and work areas, and facilities for ventilation and monitoring of airflow.

Motivation Governments and other organisations need to use social marketing and education programmes to build a Covid-safe culture and identity so that Covid-safe behaviours become part of normal, everyday activities, just like road safety behaviours such as seat-belt wearing in many countries.
\end{abstract}

Every society faces different challenges when it comes to implementing these policies. This will result in differences of emphasis and priority. For example, most countries currently cannot mount comprehensive vaccination programmes and will rely on other measures. Many countries do not have the infrastructure needed to mount extensive social media campaigns. In some countries, the scope for using outdoor spaces is very limited at certain times of the year.

These differences mean that every country and jurisdiction will need to find its own implementation strategy, monitor its success, and adjust it accordingly. Involvement of all major stakeholders will be essential, including community groups, trade unions, and other parts of civil society.

\title{
Conclusions
}

As the world enters a new phase in the Covid-19 pandemic, countries need to develop strategies to maximise the adoption of Covid-safe behaviours. These need to be commensurate with progress in human development, reducing poverty and inequality, and combating other global crises such as climate change. Embedding new behaviour patterns into everyday lives requires ensuring that people have the capability, opportunity and motivation to enact them. This means making them normal, easy attractive and routine (NEAR). Every country and jurisdiction will have unique challenges to achieving this for each risk mitigation behaviour and the responsibility lies with all major stakeholders, including government, business and civil society to developing and implement effective policies.

\section{References}

1. `Vernon J Lee, Ximena Aguilera, David Heymann, Annelies Wilder-Smith, et al. (2020).Preparedness for emerging epidemic threats: a Lancet Infectious Diseases Commission. The Lancet Infectious Diseases, vol. 20 (1), 17-19. doi:10.1016/s1473-3099(19)30674-7.

2. a, b, c, d Susan Michie, Robert West. (2020). Behavioural, environmental, social, and systems interventions against covid-19. BMJ. :m2982. doi:10.1136/bmj.m2982

3. ^J. Reason, Donald Eric Broadbent, Alan David Baddeley, J. Reason. (1990). The contribution of latent human failures 
to the breakdown of complex systems. Philosophical Transactions of the Royal Society of London B, Biological Sciences. 327(1241):475-484. doi:10.1098/rstb.1990.0090

4. 'John R. Wilmoth. Human Longevity in Historical Perspective. 4th ed. In: Physiological Basis of Aging and Geriatrics. 4th ed.: CRC Press 2007. ISBN 978-0-429-12494-5

5. 'David T. Levy, Zhe Yuan, Yuying Luo, Darren Mays. (2018). Seven years of progress in tobacco control: an evaluation of the effect of nations meeting the highest level MPOWER measures between 2007 and 2014. Tobacco Control. 27(1):50-57. doi:10.1136/tobaccocontrol-2016-053381PubMed PMID: 27956650

6. 'A. Shalom Hakkert, Victoria Gitelman. (2014). Thinking about the history of road safety research: Past achievements and future challenges. Transportation Research Part F: Traffic Psychology and Behaviour, vol. 25 , 137-149. doi:10.1016/j.trf.2014.02.005.

7. 'Mark É. Czeisler, Michael A. Tynan, Mark E. Howard, Sally Honeycutt, Erika B. Fulmer, et al. (2020). Public Attitudes, Behaviors, and Beliefs Related to COVID-19, Stay-at-Home Orders, Nonessential Business Closures, and Public Health Guidance - United States, New York City, and Los Angeles, May 5-12, 2020. MMWR Morb Mortal Wkly Rep. 69(24):751-758. doi:10.15585/mmwr.mm6924e1PubMed PMID: 32555138; PubMed Central PMCID: PMC7302477

8. ^Robert West, Susan Michie, G. James Rubin, Richard Amlôt. (2020). Applying principles of behaviour change to reduce SARS-CoV-2 transmission. Nature Human Behaviour. 4(5):451-459. doi:10.1038/s41562-020-0887-9

9. `SPI-B: Sustaining behaviours to reduce SARS-CoV-2 transmission, 22 April 2021. In: GOV.UK [Internet]. [cited 15 Jul 2021]. Available from: https://www.gov.uk/government/publications/spi-b-sustaining-behaviours-to-reduce-sars-cov-2transmission-30-april-2021/spi-b-sustaining-behaviours-to-reduce-sars-cov-2-transmission-22-april-2021

10. ${ }^{a, b}$ Robert West, Susan Michie, Paul Chadwiock, Lou Atkins, Fabiana Lorencatto. (2020). Achieving behaviour Change: A Guide for National Government. London: Public Health England 2020. Available from: https://assets.publishing.service.gov.uk/government/uploads/system/uploads/attachment_data/file/933328/UFG_Nation al_Guide_v04.00_1___.pdf 